\title{
Bildung ontem e hoje: restrições e perspectivas
}

\author{
Bildung yesterday and today: restrictions and prospects
}

Pedro Goergen*

\section{Resumo}

O propósito do presente texto é avaliar o sentido e as implicações do uso contemporâneo do conceito de Bildung. A análise abrange três tópicos, sendo o primeiro relativo às vertentes históricas do conceito de Bildung; o segundo, uma caracterização de alguns dos elementos mais relevantes da realidade educacional contemporânea; e, o último, uma reflexão sobre os limites e os possíveis aportes do conceito de Bildung para a formulação de um projeto pedagógico na contemporaneidade. Sugere-se que o aproveitamento de alguns aspectos do projeto educacional conhecido como Bildungstheorie pode ser produtivo como parâmetro crítico e reorientador da educação na atualidade.

Palavras-chave: Bildung. Formação contemporânea. Formação moderna. Teoria educacional.

\section{Abstract}

The purpose of this paper is to evaluate the meaning and implications of the contemporary use of the concept of Bildung. The analysis covers three topics, the first concerning the historical aspects of the concept of Bildung; The second a characterization of some of the most relevant elements of contemporary educational reality; and the latter a reflection on the limits and possible contributions of the concept of Bildung for the formulation of a pedagogical project in the contemporary world. It is suggested that the use of some aspects of the educational project known as Bildungstheorie can be productive as a critical and reorienting parameter of education today.

Keywords: Bildung. Contemporary formation. Modern formation. Pedagogy.

Recebido em: 15/02/2017 - Aprovado em: 30/06/2017

http://dx.doi.org/10.5335/rep.v24i3.7758

Doutor em Filosofia pela Ludwig Maximilians Universität München. Realizou pós-doutorado na Universidade de Bochum e no Instituto Max Planck da Alemanha. É professor titular da Universidade de Sorocaba e professor titular (colaborador) da Universidade Estadual de Campinas. E-mail: pedro.goergen@hotmail.com 


\section{Introdução}

Para responder à pergunta-tema deste dossiê sobre a despedida ou o renascimento da Bildung, parece-me necessário, num primeiro momento, explicitar o próprio sentido histórico de Bildung, nem sempre muito claro num contexto cultural distante de seu surgimento. Um segundo passo que estimo relevante é destacar os traços históricos, políticos, econômicos e culturais contemporâneos que marcam e condicionam a atualização desse conceito. Por último, é importante refletir sobre os sentidos teórico-práticos da ideia de Bildung ainda significativos na contemporaneidade. São esses três pontos que tentarei analisar neste desenho inicial e exploratório do meu recorte temático sobre a "dimensão filosófico-pedagógica da formação".

Iniciarei destacando alguns aspectos teórico-históricos do conceito de Bildung, apoiando-me em um trabalho de Clemens Menze, reconhecido especialista da área, intitulado "W. v. Humboldts Lehre und Bild vom Menschen", publicado em 1970. ${ }^{1}$ Na sequência, destacarei a necessária re-historização do conceito (Bildung), criado e usado no decorrer dos séculos XVIII e XIX, como condição de sua fecundidade atual em circunstâncias socio-históricas tão distintas daquelas de sua origem. Por último, pretendo analisar as dimensões e os déficits formativos contemporâneos, na perspectiva do ser humano integral, destacando os aspectos biológico, ético, racional e estético como elementos centrais da formação integral do ser humano na contemporaneidade.

Trata-se, portanto, de um recorte, ainda em seus primeiros delineamentos, de um trabalho mais amplo e sistemático a ser desenvolvido, no médio prazo, sobre o tema "Despedida ou renascimento da Bildung". Minha intenção é explorar a dimensão filosófico-pedagógica dessa temática mais ampla. Assim sendo, o que o leitor encontra no presente texto não é o resultado de uma investigação já concluída, mas um primeiro esboço de uma pesquisa mais ampla, com a participação de vários pesquisadores, da Alemanha, da Argentina e do Brasil, que exploram outras dimensões dessa mesma temática. No momento, devo me restringir ao primeiro e ao segundo pontos referidos e, ainda assim, sem a pretensão de responder de forma profunda e detalhada à pergunta-tema do projeto de pesquisa sobre a "Despedida ou renascimento da Bildung".

Minha tese inicial, a ser confirmada ou revogada ao longo do estudo, é que não se trata nem de despedida nem de renascimento da ideia de Bildung. Trata-se, primeiro, de um repensar do processo formativo contemporâneo à luz das teses filosóficas, antropológicas e formativas, desenvolvidas por pensadores como Rousseau, Kant, Fichte, Herbart e outros, adensadas no projeto de uma Bildungstheorie, 
projetada por Wilhelm von Humboldt. E, segundo, da análise dos sentidos e das possibilidades desta Bildungstheorie, ou teoria educacional, no mundo atual, profundamente diferente da realidade social e cultural do século XIX.

Inicio, então, assinalando alguns aspectos relativos ao conceito de Bildung, especialmente nos séculos XVIII e XIX, na Alemanha. Segundo Clemens Menze, antes de o conceito de Bildung alcançar significado pedagógico em sentido estrito, ele já havia percorrido longa história. Sua trajetória parte da visão especulativa e teológico-mística de Meister Eckardt (1260-1328), passando pelo espírito renascentista, pelo momento místico/natural, pela doutrina de vida de Paracelsus (1493-1541) e pela teosofia de Jakob Boehme (1575-1624). Para o místico Meister Eckardt, Bildung significa o encaminhamento da alma ao criador, ou seja, o movimento da relação da alma com Deus. Nesse sentido, a Bildungslehre, a doutrina da formação, ancorava-se na metafísica e na teologia. Esta concepção teve influência até o século XVIII, com alguma ressonância posterior, ainda perceptível em Fichte.

Na filosofia natural e na doutrina de vida de Paracelsus, contemporâneo de Leonardo da Vinci (1452-1519), Erasmo de Rotterdam (1466-1536) e Martinho Lutero (1483-1546), no contexto do movimento humanista/renascentista do século XVI, Bildung significa o desenvolvimento das disposições interiores, vindas de Deus. Esta concepção guarda certa afinidade com a ideia aristotélica de entelechia (o estado de perfeição de cada indivíduo por força do qual ele se desenvolve segundo leis próprias) e, nesse sentido, distancia-se da metafísica de Meister Eckardt. O "desenvolvimento das forças" é curso de conflitos interiores, expresso em conteúdos sensitivos. A Bildung se baseia na natureza criativa e recriativa desse processo, sem que esta conduza diretamente o vir a ser do homem, uma vez que Deus é, na verdade, o verdadeiro mentor do processo. Tal conceito de Bildung teve, apesar da resistência do "cristianismo prático" do pietismo, forte influência sobre o pensamento alemão durante os séculos XVII e XVIII, até o Romantismo.

A doutrina teosófica de Jakob Böhme (1575-1624), por sua vez, considera Bildung o despertar e o desenvolvimento ativo de imagens e representações internas da pessoa e entre as pessoas. Inicia-se, assim, o curso da autonomia pessoal, marco central da modernidade, cuja origem radica na ideia da relação entre palavra e formação pessoal, já presente em De Magistro, de Santo Agostinho. ${ }^{2}$ Assim se constitui historicamente o conceito pré-clássico de Bildung, próximo do sentido de formação do esclarecimento posterior.

A passagem do conceito de Bildung para a linguagem especializada ocorre em meados do século XVIII, na pedagogia do esclarecimento. Nessa época, a ideia de Bildung passa a ser formulada nos termos da linguagem disciplinar da pedagogia, ${ }^{3}$ 
tornando-se, no curso do distanciamento do paradigma teológico, metafísico e místico anterior, o conceito-chave da educação e do ensino. É surpreendente observar que o surgimento do conceito de Bildung na educação ocorreu somente no século XVIII, sendo que a analogia entre a formação e a produção artística e manual (techne) já existia desde Platão.

Uma explicação possível desse lapso histórico pode ser encontrada na tradicional passividade do ser humano frente aos desígnios divinos e no fato de que o surgimento da relação ativa entre Bildung e educação (formação) só veio a ocorrer no contexto da emancipação do Terceiro Estado, ou seja, no movimento burguês e em seu distanciamento crítico frente à teologia e à metafísica, ou seja, frente às ideologias das classes dominantes do clero e da nobreza. Nesse contexto, trata-se de uma oposição às relações de poder limitantes da condição humana, na qual a Bildung eleva o homem ao nível do racional, libertando-o da condição de mera função das relações de poder.

Nesse decurso histórico, debulha-se o conceito de Bildung, relacionado à emergência da razão como elemento distintivo do humano, espelhando, de alguma maneira, o racionalismo cartesiano e a metafísica do poder de Leibniz (1646-1716), próprios do Iluminismo. Em outros termos, a filosofia do esclarecimento gerou o horizonte cultural no qual as novas discussões relativas à formação encontram espaço e amparo. Também a teoria do desenvolvimento presente na filosofia iluminista de Christian Wolf (1679-1754) ${ }^{4}$ favoreceu a concepção de Bildung como desenvolvimento das forças naturais da alma. Em Kant (1996), já encontramos clara menção não só à necessidade da intervenção racional, mas também à necessidade da ajuda de uma razão exterior, para alcançar a superação de sua animalidade.

Ao longo desse percurso histórico, a Bildung perde sua aura mística e se assume como relação planejada e direta subjetiva ou entre educador e educando, a partir de um objetivo preestabelecido. Nesse novo momento, Bildung se funda sobre o pressuposto da natural fragilidade e dependência próprias da natureza humana e da consequente necessidade do homem de se conduzir e ser conduzido no processo de sua realização e integração social. "Bildung designa a tensão entre o natural ponto de partida da educação, seu termo final, e as medidas necessárias com vistas ao aperfeiçoamento intelectual e à serventia social" (MENZE, 1970, p. 137). Em termos estritamente pedagógicos, o conceito de Bildung significa, agora, a formação do homem virtuoso mediante influência externa à luz do conceito de cultura e civilização, atinentes ao progresso do mundo.

Mesmo assim, nesta época, a individualidade, a linguagem e a historicidade ainda permanecem desconsideradas, e é no contexto dessas carências que nasce, como reação, a Bildungstheorie (teoria da formação) do humanismo alemão. Fundamental para a nova concepção de educação é a influência de Rousseau (1712-1778), sobretu- 
do porque o pensador francês, acreditando na perfectibilidade do ser humano, ${ }^{5}$ abre espaço para o estabelecimento de regras e orientações pedagógicas, animadas por postura crítica frente à realidade desumana do seu tempo e engajadas na constituição política e utópica de uma nova sociedade mais humana de homens livres.

No entanto, há o reconhecimento de que, para a realização de tal propósito, a teoria da formação não pode perder de vista que o objetivo da transformação social pela formação do indivíduo deve partir das condições concretas do seu tempo, sem, contudo, acondicionar-se a elas. O distanciamento crítico da realidade é o espaço no qual as transformações almejadas podem ocorrer, razão pela qual o não conformismo e o distanciamento crítico se tornam elementos constitutivos da Bildung.

Nesse período de ouro da filosofia e da poesia alemãs, adensa-se a fundamentação de uma teoria da educação focada na autoformação, já preconizada por Rousseau. É o desenvolvimento da innerliche Kraft, da disposição ou força interior, livre de influências exteriores. Mesmo reconhecendo ser impossível evitar que a pessoa humana se configure na interconectividade entre as disposições interiores e a realidade externa, o ideal da Bildung reforça a ideia de autoformação. Nesse sentido, pode-se dizer que Bildung é o mesmo que autoformação. No entanto, esta autoformação supera seu caráter místico e se "assume como uma intervenção planejada do educador com objetivo determinado" (MENZE, 1970, p. 137). ${ }^{6}$ Sobre esta base se constitui a teoria educacional do humanismo alemão, que, ao contrário do que muitas vezes se pensa, é crítica com relação à realidade da época, na busca de uma nova sociedade mais humana. "Ela é, portanto, política e utópica e se compromete com a nova determinação do homem como um ser de liberdade" (MENZE, 1970, p. 138). Esta observação assume significativa relevância na medida em que relativiza a imagem romântica, não raro, agregada à ideia de Bildung. Já naquela época, tinha-se clara consciência de que a Bildung, para alcançar seu objetivo de transformação, não poderia deixar de levar em conta a realidade social concreta. $O$ conhecimento e o distanciamento crítico da realidade são, pois, elementos centrais da Bildung desde sua primeira hora. ${ }^{7}$

Herder (1744-1803) foi o primeiro pensador a defender esta ideia, acreditando numa história da humanidade cujo centro é realização do ser humano, mas tendo como elemento central a autoformação baseada em dois aspectos principais: a língua e a história. A própria história é entendida como o processo do desenvolvimento do humano, no qual:

[...] todas as instituições, todas as ciências e artes não têm outro objetivo senão humanizar, isto é, transformar o não-ser humano ou o meio-ser humano em ser humano inteiro, conferindo, aos poucos, à raça humana a forma que a razão deseja, o dever exige e a humanidade almeja (HERDER, 1994, apud MENZE, 1970, p. 139, grifo nosso). 
Embora muito criticadas, estas ideias de Herder continuam presentes até hoje na teoria pedagógica.

Nesses termos, a concepção pedagógica do conceito de Bildung leva, no final do século XIX, à consagrada formulação programática de Bildunstheorie, ou seja, uma "teoria da formação", com a finalidade maior de desvelar os fundamentos de uma ciência cujo objetivo seria expressar o ser, o vir a ser e as determinações do ser humano. Embora essa concepção ampla de uma disciplina nunca tenha sido concretizada, tornaram-se visíveis as linhas gerais de um projeto de tal natureza. A partir desse momento, a teoria da formação é concebida como uma ciência que visa reunir, num todo, as facetas do tornar-se humano e as possibilidades da influência e da ajuda externas na realização desse processo.

Wilhelm von Humboldt é o primeiro a assumir o desafio de desenvolver tal projeto. Embora seu texto clássico "Sobre a organização interna e externa das instituições científicas superiores em Berlim" se refira mais especificamente às instituições de nível superior, os princípios referentes à Bildung e à perfectibilidade dizem respeito à formação do homem como um todo. Humboldt confere centralidade à ciência como "produção do conteúdo responsável pela formação intelectual e moral" do ser humano (HUMBOLDT, 1977, p. 39). No entanto, as instituições científicas apenas se justificam plenamente quando elas atendem aos interesses de enriquecimento moral da nação. Essa delimitação explica-se pelo déficit alemão de desenvolvimento nacional, relacionado aos cargos políticos assumidos pelo próprio Humboldt, no contexto da emergência do próprio Estado moderno. Mas, independentemente disso, não se deve esquecer que tal preocupação já estava presente em Erasmo de Rotterdam, em Lutero e em Fichte, como mostram os Os discursos a nação alemã (1977), deste último. Nesse contexto, é importante não esquecer que este discurso político geral, referente ao desenvolvimento da nação alemã, pressupõe formação dos indivíduos.

Humboldt é o primeiro a assumir a tarefa de realizar uma teoria da formação. Até aquele momento, assim constata o próprio Humboldt, existia apenas uma teoria da educação com seus preceitos e normas, mas não uma teoria da formação relativa à vida humana e às relações sociais, ou seja, uma teoria referente aos princípios antropológicos fundantes, dos quais os regulamentos expressos na teoria da educação são apenas aplicações circunstanciadas. Faltava, portanto, uma verdadeira fundamentação filosófica da formação do humano. Mesmo assim, ainda que ao estabelecimento desses fundamentos não seguissem reformas morais reais e efetivas, estava sendo preenchido um grande vazio existente na enciclopédia de nossas ciências. 
Todo o esforço em prol de melhorias práticas, orientadas pelo acaso e pelo sentimento, embora louvável, carecia de abrangência e profundidade por falta de embasamento sobre o chão firme de uma teoria da formação. Humboldt assumiu o projeto de elaborar um plano sistemático e estratégico de uma teoria da educação. Segundo lembra Menze (1970, p. 139), em outubro de 1793, Humboldt escreve que "[...] almeja ver o conhecimento sobre o homem e os princípios de sua formação tratados em todo seu conjunto", visto que, até aquele momento, apenas existia uma teoria da educação e da legislação, mas não uma teoria da formação (Bildungstheorie). Esta falta de clareza a respeito dos fundamentos gerais da formação era, no entender de Humboldt, a razão das inconsistências legais no campo da educação. Mais tarde, ele mesmo chegaria à conclusão de que uma teoria filosófica da formação só poderia ser formulada com base em conhecimentos filosófico-empíricos do ser humano. Somente a fundamentação teórico-filosófica bem fundamentada do vir a ser humano poderia dar consistência tanto à regulamentação social do processo formativo quanto à formação do indivíduo em si.

Para Humboldt, a teoria da formação deveria incluir: a) a ciência dos princípios, explicitando tanto a possibilidade quanto a validade dos fundamentos da formação; b) as teorias sobre as principais dimensões do humano no mundo, com vistas ao significado do tornar-se ser humano; e c) uma abrangente investigação empírica que, com a ajuda de métodos empírico-científicos, revelasse os dados e fatos indispensáveis para o início da transformação de cada indivíduo. Na verdade, Humboldt só conseguiu desenvolver alguns aspectos deste abrangente programa; entre eles: a avaliação do significado e do papel do Estado para o homem; o significado da antiguidade clássica e da literatura do seu tempo, como também da estética de modo geral; as tentativas de fundamentação de uma antropologia comparada; e, também, a necessidade de estudos fisionômicos e da teoria de gênero para a teoria da formação.

Outra dimensão da fundamentação de uma teoria da formação está nas investigações de Humboldt sobre a linguagem, que, para ele, representa o grande poder de intermediação entre o homem e o mundo. Mediante a linguagem, o mundo se torna um mundo humano, e, nesse sentido, a aprendizagem da língua significa o autoaperfeiçoamento e a conquista do mundo ao mesmo tempo. Tanto as considerações sobre linguagem quanto as reflexões filosóficas de Humboldt têm seu ponto de partida na experiência. Ele mesmo declara que sua teoria, embora de natureza teórico-filosófica, deve abranger o espaço intermediário da tensão entre as ciências empíricas e as ciências especulativas. Este senso de realismo envolve também os aportes de muitos pensadores anteriores e contemporâneos a Humboldt, cujas ideias são reinterpretadas num novo contexto de sentido, no qual a teoria 
da formação pode ser considerada, pela primeira vez na história do pensamento pedagógico, como uma disciplina científica autônoma.

O texto já mencionado anteriormente, "Sobre a organização interna e externa das instituições científicas superiores em Berlin", ainda que diretamente focado no papel da universidade, traduz o conceito de "formação humana", assumido por Humboldt. Nele encontram-se as ideias de conhecimento, autonomia, liberdade, progresso e cooperação. Dimensões estas que se congregam em torno do objetivo de construção do Estado-Nação, condição essencial para a superação do absolutismo político. A educação, não apenas a de nível superior, estava sendo convocada para prover as mudanças políticas com o substrato cultural, epistêmico e moral dos indivíduos e da sociedade. Humboldt enuncia os elementos teórico-educacionais que deveriam dar sustentação humana ao projeto político de construção do Estado alemão, em atraso frente aos outros Estados europeus.

Não se trata, é claro, de um projeto isolado de Humboldt, pois Kant (17241804), Herder (1744-1803), na Alemanha, Voltaire (1694-1778), Condorcet (17431794) e Turgot (1727-1803), na França, discutiam temas semelhantes na segunda metade do século XVIII. Trata-se de invocar as luzes da razão, ou seja, a filosofia e a ciência, para dar sustentação ao novo projeto civilizatório, moderno e secularizado, então em curso. $\mathrm{O}$ centro desse debate era a explicitação dos vínculos que se enunciavam entre a ideia de progresso, fulcro e promessa do Iluminismo, e a educação, como estratégia de sua realização.

Esta ideia de "progresso" tornou-se o conceito condutor do grande movimento de passagem cultural entre o período teológico-feudal-absolutista e o novo estágio racional-secularizado-democrático da modernidade. O progresso se funda no poder da razão e dispensa quaisquer outros recursos teológico-metafísicos para a condução da vida humana na perspectiva da perfectibilidade individual e social. Um papel central neste novo projeto social cabia à educação, constituindo, assim, a interdependência entre as ideias de progresso e educação como forças condutoras de um novo modelo de desenvolvimento, racionalmente assegurado, das disposições humanas.

Esta ideia de marcha, continuada e progressiva, da humanidade tornou-se, por assim dizer, consensual, sendo assumida igualmente por posturas opostas, como o idealismo kantiano e o materialismo marxiano. A destinação humana à perfeição teria encontrado as estratégias para a sua gradual e contínua realização. A formação humana seria o elemento-chave da formação do homem novo, substrato de uma nova sociedade. Segundo as palavras de Condorcet, 
[...] a natureza não indicou nenhum limite ao aperfeiçoamento das faculdades humanas; a perfectibilidade do homem é realmente indefinida: que os progressos dessa perfectibilidade, doravante independente da vontade daqueles que desejariam detê-los, não têm outros termos senão a duração do globo onde a natureza nos lançou (CONDORCET, 1993, p. 20-21).

Nesse mesmo sentido, também Kant afirma que o "[...] progresso sem dúvida será às vezes interrompido, porém, jamais detido" (1986, p. 53).

É bom lembrar que Humboldt e os demais formuladores do conceito de Bildung escreveram em circunstâncias históricas determinadas, e, como não poderia deixar de ser, suas teorias têm as marcas do seu tempo. Ora, nosso tempo não é o de Humboldt, por esta razão, uma tradução literal de suas teorias seria pouco produtiva. De outra parte, sabemos que a história não é de natureza linear, segmentada, razão pela qual o passado sempre sobrevive no presente, não apenas como lembrança, mas como elemento constitutivo. Daí o sentido da pergunta condutora desta reflexão: "despedida ou renascimento da Bildung?".

Em princípio, entendo que, postas assim, como alternativas excludentes, não se trata nem de despedida, nem de renascimento. Não é "despedida" porque, conforme busquei argumentar, a Bildung oferece uma série de elementos histórico-filosóficos ainda hoje relevantes para se pensar a formação humana, mas também não se trata de simples "renascimento", porque hoje a realidade sociocultural e econômica é muito diferente daquela dos tempos de Humboldt, e é no contexto desta realidade que o ser humano deve se formar (bilden). Na sequência, desejo fundamentar melhor esta conclusão desde a perspectiva contemporânea.

II

A primeira questão a ser posta, lembrando o que expus anteriormente, é que, de um lado, a Bildung está inserida num determinado contexto histórico e, portanto, traz as suas marcas históricas e mesmo políticas. Ora, a realidade contemporânea é profundamente distinta daquela de Humboldt ou da de outros pensadores que lançaram os fundamentos da concepção clássica de Bildung. A primeira questão importante a ser mencionada talvez seja a decepção que hoje se dissemina com relação à narrativa moderna, cuja visão positiva começou a se constituir nos tempos de Humboldt e já colocava grandes esperanças na racionalidade científica por ele incorporada no próprio contexto da Bildung. Aparentemente, nesta esperança se coligavam o progresso da razão e a realização do ser humano. Hoje, estamos assustados com a discrepância profunda que se evidencia entre esses dois termos, como nos mostram Adorno e Horkheimer (1985), na Dialética do esclarecimento.

Outro aspecto a ser considerado, em termos das diferenças de época, é a esperança da espiritualidade, o sentido maior da própria plenitude do ser humano, cuja realização ocupava o centro do chamado classicismo alemão. Hoje, ao con- 
trário, predominam os interesses materiais, a posse, o dinheiro e a bem-sucedida integração sistêmica como fontes de realização e felicidade do humano. Colocar a realização espiritual como o objetivo maior seria como falar a ouvidos moucos de pessoas que trocam a alma pelo dinheiro e pelo poder de consumir. Ao contrário do Fausto de Goethe, que vende sua alma ao demônio pelo direito de conhecer mais, hoje, os heróis trocam a alma pelo direito de consumir mais.

Se a educação for definida, conforme Adorno (1995, p. 141), como "a produção de uma consciência verdadeira", corre-se o risco de se perder num tal nível de abstração e generalidade que desempodera a educação frente ao sentido prático, diverso e múltiplo de sua atuação. Os termos "consciência verdadeira" lembram o posterior "consenso" habermasiano, que, mesmo no interior de sua própria orientação epistêmica, foi submetido a severas críticas, como aquelas apresentadas por Axel Honneth (2012) no seu texto Befreiung aus de Mündigkeit (Libertação da autonomia).

O discurso que, desde os gregos, diz que a educação pode e deve conduzir a consciência individual ao encontro de uma realidade transcendente não é mais aceito num contexto cultural em que a polivalência de concepções de mundo, de posturas éticas, de religiões e filosofias muito divergentes invoca direitos iguais. $\mathrm{O}$ universalismo, quase obrigatório da modernidade, que, de um modo ou de outro, ainda dava as cartas ao tempo da Bildung clássica, parece hoje definitivamente estremecido. Em outras palavras, pressupõe-se, atualmente, que devem ser admitidas respostas não convergentes sobre o que é o homem, a sociedade e a verdade. Segundo Honneth (2012, p. 133), o imaginário essencialista (Einheitsvorstellung) da tradição europeia está ameaçado pelo desejo de liberdade e protesto contra ordenamentos identitários convencionais. O próprio conceito de justiça implica, hoje, a aceitação do não idêntico nos campos da filosofia, da moral, da política e da antropologia.

Hoje sabemos que estamos longe, se não definitivamente afastados, da densidade de tais pressupostos filosóficos, culturais e mesmo éticos tradicionais, e que compete a nós, não só pelo diálogo convergente, como queria Habermas, mas também pelo conflito dissonante, como propõe Honneth, aproximarmo-nos, no interior do processo histórico, do ideal, sempre provisório, de homem, de sociedade e de mundo. Os contextos plurais, que merecem respeito, não mais autorizam interpretações e enunciados peremptórios, passíveis de serem aceitos e muito menos impostos a todos. Há, nesse sentido, uma enorme distância entre um contexto histórico em que consciência e verdade eram suscetíveis de elaboração ordenada e coerente de um sistema de ideias e princípios supostamente mais verdadeiros e corretos, e o contexto contemporâneo em que os fundamentos e valores universais 
se encontram num conflituoso processo de relativização, quando não de dissolução, aparentemente irreversível.

A modernidade se propôs, inicialmente, a substituir os princípios metafísicos e religiosos por outros racionalmente fundamentados, mas ainda portadores da metafísica da universalidade impositiva. Sabemos hoje que tal universalismo ético/ epistêmico, subjacente ao racionalismo moderno, está, se não de vez falido, pelo menos profundamente questionado e abalado. É no interior desta realidade pós-metafísica que devemos falar de consciência e verdade, em perspectiva de transcendência historicamente condicionada. A modernidade nos deixa, por assim dizer, diante de um cenário de perplexidade no que diz respeito aos princípios fundantes de nosso pensar e agir. O projeto de emancipação racional, até pelos cenários de violência, feiura, dor e morte que nos legou, foi incapaz de produzir ou explicitar, pelo menos não de maneira convincente e cativante, pressupostos orientadores que sustentem, em base exclusivamente racional, um horizonte de emancipação racional e ética. A perfeita e segura integração entre verdade e ação, ou seja, entre teoria e prática, para o alcance de fins humanos já não é aceita, o que, porém, não significa que ela não seja necessária, ainda que deva ser sempre construída e reconstruída no contexto de cada provisoriedade histórica.

Nesse sentido, quando falamos, no campo da educação, de tempos pós-metafísicos, na verdade, estamos falando de algo muito radical e aberto, mas não estamos declinando da absoluta necessidade de transcendências como incontornáveis supostos da convivência humana e da preservação do nosso ambiente de vida. Por isso, estamos desesperadamente em busca de fundamentos éticos sobre os quais possamos assentar as orientações políticas, jurídicas e pedagógicas da vida humana, individual e social.

O humanismo moderno pressupõe a natural possibilidade de uma consolidação racional dos fundamentos e acordos com o desejo e a busca de felicidade. Até o momento, mais nos afastamos do que nos aproximamos da ideia de um ser humano e de uma sociedade congregados em torno de uma versão laica e racional da bem-aventurança, antes embasada em princípios filosóficos, metafísicos ou religiosos. Ao contrário, o que atualmente predomina é o direito à autonomia e à liberdade cultural ou mesmo individual como fundamento de verdade. No mundo globalizado em que as verdades particulares se avizinham e precisam conviver, surgem conflitos para os quais não encontramos solução. Este "sofrimento de indeterminação" leva Axel Honneth (2003) a falar de "luta por reconhecimento". A ideia de felicidade, ainda sobrevivente em meio à derrocada dos princípios metafísicos, parece não mais se vincular ao ideal de felicidade individual e coletiva, mas ao funcionamento e ao "bem-estar" do sistema e, por esta via, da elite. É no sistema, leia-se 
sistema econômico, que o ser humano deve encontrar sua felicidade. É o sistema que constitui o horizonte e que agrega "dignidade e felicidade" ao humano. Quem não se integra ou é rejeitado por não corresponder às expectativas sistêmicas não encontra realização nem felicidade.

Esta ausência de felicidade fora do sistema, longe de ser casual, é a mais cabal e forte estratégia de poder. O ser humano, enquanto ser humano em si, tornou-se vazio de sentido, visto que seu sentido é inerente ao pertencimento sistêmico, como mostram P. Dardot e C. Laval (2016), no seu livro com o sugestivo título de A nova razão do mundo. Este vazio marca a nossa atualidade, a atualidade de esperança perdida, a esperança da promessa perdida. Este me parece ser o cenário do sentido humano e o ideal de formação na contemporaneidade. Felicidade, realização humana, dignidade, respeito, reconhecimento estão essencialmente condicionados à integração sistêmica. A pergunta que se impõe por si só é: como educar para a emancipação neste contexto histórico? A resposta encontrada até o momento é uma educação instrumental que faz do homem um elemento da maquinaria do sistema. No entanto, torna-se cada vez mais claro que, para recuperar a esperança perdida, não basta seguir a mesma trilha autorreferenciada da razão instrumental que levou à dissolução da consciência, da subjetividade e da substância ética.

A Bildung, conforme formulada e desejada nos séculos XVIII e XIX, perdeu sua força e seu vigor num mundo totalmente administrado no qual também a consciência do homem é determinada pela ordem, pela economia, pelo sistema. A adaptação torna-se não só o fim e a estratégia da educação, mas também o próprio fim e sentido do humano. De certo modo, inverte-se o fluxo das ideias que, na compreensão da Bildung, seguiam do interior para o exterior, agora, elas vêm do exterior para o interior, transformando a influência externa em polo determinante da constituição do humano. Essa relação invertida transforma a consciência em falsa consciência, que reflete a realidade e perde sua prerrogativa de liberdade e autonomia. $\mathrm{O}$ sujeito se livra de sua responsabilidade crítica frente ao sistema, e o sistema se livra do sujeito incômodo, podendo seguir seu rumo preestabelecido.

Torna-se, assim, impossível a realização da experiência constitutiva da subjetividade, conforme contatam Adorno e Horkheimer (1985). E, segundo Leopoldo e Silva, "[...] o sujeito não pode ser concebido separadamente de sua própria experiência e esta só pode ser concebida como o dinamismo de formação do sujeito por via da auto reflexão" (1914, p. 90). A realidade determina a consciência, impedindo que esta se antecipe e influencie os rumos da sociedade, do mundo e da história. Perde-se, assim, a relação dialética transformadora, que somente pode emergir da relação entre realidade e sujeito. Em suma, trata-se de reconquistar a possibilidade da experiência, ou seja, de contradição e resistência transformadora do 
sujeito e da realidade. Emancipação, nesse sentido, não significa isolamento, nem identificação do sujeito com a realidade; significa distanciamento crítico, visando à transformação subjetiva e objetiva com vista à abertura de novas possibilidades históricas, mais condizentes com as condições e as expectativas humanas. Nos termos de Franklin e Silva,

[...] as experiências humanas moldam a história, e a história molda as experiências humanas; não se trata de um círculo vicioso, mas da própria função da historicidade, cujo sentido está na relação dialética que a liberdade mantém com as determinações. De modo que devemos compreender que a experiência da subjetividade, da formação e da autonomia se constitui ou se desconstitui no rumo histórico da humanidade e a partir de condições objetivas $(1914$, p. 94$)$.

O ideal da formação, nos termos da Bildung, partia do pressuposto de uma forte autonomia do sujeito com relação à realidade. Hoje, certamente, pendemos para o extremo oposto, na medida em que o homem abre mão de sua liberdade e se submete ao real, ao sistema. Talvez a formação deva ser pensada não como liberdade, nem como submissão em relação à realidade, mas como relação dialética de ancoragem e superação. A Bildung clássica ainda estava estreitamente referenciada a ideais absolutos, talvez não a-históricos, mas, contudo, supra-históricos e, nestes termos, a Bildung tendia a acentuar a transcendência, esquecendo seus laços de imanência. Hoje, vivemos a imanência e esquecemos a transcendência, como se a história fosse regida por uma necessidade cega que força o humano à resignação ou à alienação. Ambas as posturas esquecem a noção de conflito inerente à história: o conflito entre a positividade e a possibilidade, entre o tópico e o utópico, entre o lugar e o não lugar. Em termos formativos, isso representa a oposição entre conformação e alienação.

A conformação esquece o processo de instituição do presente, necessariamente ambíguo. Para escapar da necessidade imanente ao real, não é preciso recorrer aos ideais transcendentes, o que não significa, pelo menos não a meu juízo, negar a necessidade de transcendência como condição de possibilidade de autonomia frente à heteronomia. A transcendência não como a afirmação de pressupostos metafísicos supra-históricos, mas como o pensamento negativo que compreende a história e nela o ser humano, não como dado, mas como experiência e construção humana. É nessa experiência, compreendida como a relação dialética entre a imanência e a transcendência, conduzida pela consciência humana, que se constitui o processo formativo do sujeito histórico. Formação significa, nesse sentido, a arte de o sujeito se constituir historicamente na consciente articulação entre a positividade do presente, as carências do passado e as possibilidades do futuro. Hoje, predomina a ideia do presente absoluto, como superação do passado e prenúncio do futuro como sua própria continuação. O passado anuncia o presente, e o futuro é a sua continuação. 


\section{Conclusão}

Como enunciei anteriormente, este texto trata de um início de trabalho, parte de uma pesquisa mais ampla, com a participação de vários autores. Portanto, estas primeiras considerações, na verdade, não comportam uma conclusão. O que este conjunto de considerações permite dizer, neste momento, é: a) que o conceito de Bildung pode ser produtivo como referência crítica para a elaboração de um projeto contemporâneo de formação humana; b) que tal projeto pode ser fecundo e produtivo, sobretudo, frente ao cenário de objetalização e submissão sistêmica do homem, próprio do atual momento; e c) que, no entanto, este trabalho deve levar em consideração as reais contingências do contexto social, cultural e, sobretudo, econômico da atualidade, que não permitem a transferência, sem óbice, do ideal de Bildung do passado ao presente.

Em síntese, entendo que a reflexão humanística e a ética, presentes na ideia de Bildung, ou seja, a ideia de formação e valorização humana pode ser fecunda e produtiva para o desenvolvimento e o enriquecimento de uma teoria ou filosofia da educação para os tempos fluidos, materialistas e economicistas em que vivemos.

\section{Notas}

1 Visto que este texto está esgotado há muito tempo, valho-me de uma versão abreviada, publicada pelo mesmo autor (1970) sob o verbete Bildung.

2 Especialmente na obra De Magistro, em que Agostinho conversa com seu filho Adeodato sobre o tema da linguagem. A preocupação de Agostinho era com a formação de seu filho (embora este já tivesse morrido à época), ou seja, com sua Bildung.

3 Esta vertente será levada a termo por Friedrich Herbart (1776-1841), que, pela primeira vez, agregou sistematicidade, procedimentos e objetivos claros à pedagogia, dando-lhe contornos de ciência.

4 Wolf é considerado o criador da língua alemã como língua da instrução e da pesquisa acadêmica, conferindo características mais racionalistas à educação, à psicologia e à formação. Cf. Araujo (2012).

5 Sobre este tema, ver: Dalbosco (2012, p. 11-22).

6 Todas as traduções do alemão são de minha responsabilidade.

7 Este é um elemento central para o posterior debate sobre a "despedida ou renascimento da Bildung hoje".

\section{Referências}

ADORNO, T.; HORKHEIMER, M. Dialética do esclarecimento. Rio de Janeiro: Zahar, 1985.

ARAUJO, S. F. O lugar de Christian Wolf na história da psicologia. Universitas Psychologica, v. 11, p. 2013-2024, jul./set. 2012.

CASPER, G.; HUMBOLDT, W. Von. Um mundo sem universidades? Editora EDUERJ. 1977.

CONDORCET, J. A. Esboço de um quadro histórico do progresso do espírito humano. Campinas: Editora Unicamp, 1993. 
DALBOSCO, C. Perfectibilité e formação humana no pensamento de Jean-Jacques Rousseau. In: BERTOLIN, J. C. B.; SOUZA, J. C. C. de. Planejamento institucional de uma universidade comunitária. Passo Fundo: UPF Editora, 2012. p. 11-22.

DARDOT, P.; LAVAL, C. A nova razão do mundo. São Paulo: Boitempo, 2016.

FICHTE, J. G. Discursos à Nação alemã, Porto: Portoeditora, 2010.

HONNETH, A. A luta por reconhecimento. São Paulo: Editora 34, 2003.

. Das Andere der Gerechtigkeit. Frankfurt am Main: Suhrkamp Verlag, 2012.

HUMBOLDT, W. V. Sobre a organização interna e externa das instituições científicas superiores em Berlim. In: CASPER, G.; HUMBOLDT, W. von. Um mundo sem universidades? Rio de Janeiro: EDUERJ, 1997.

KANT, I. Sobre a pedagogia. Piracicaba: Unimep, 1996.

. Teoria y practica. Madrid: Tecnos, 1986.

LEOPOLDO E SILVA, F. Universidade, cidade e cidadania. São Paulo: Hedra, 1914.

MENZE, C. Bildung. In: SPECK, J.; WEHLE, G. Handbuch pädagogischer Grundbegriffe.

Munique: Kösel Verlag, 1970. v. 1. p. 134-184. 